\title{
Parallel between Offline-SPE-LC-MS and Direct Injection LC-MS Methods for Acrylamide Detection in Drinking Water at Parts Per Trillion Level
}

\author{
FLORENTINA LAURA CHIRIAC, IULIANA PAUN, FLORINELA PIRVU, LILIANA CRUCERU, LUOANA FLORENTINA PASCU, \\ TOMA GALAON* \\ National Research and Development Institute for Industrial Ecology ECOIND, 71-73 Drumul Podu Dambovitei Str., 060652, \\ Bucharest, Romania
}

\begin{abstract}
The presence of acrylamide, a potential human carcinogen, in treated drinking water has been a long-time concern for public health agencies. Due to this, acrylamide is included among the substances to be monitored in drinking water with a stated maximum admissible level of $0.1 \mu \mathrm{g} / \mathrm{L}$ in Europe. The necessity for ultra-trace level detection of acrylamide has led to development of an Offline-SPE-LC-MS method that involves SPE extraction of acrylamide using a strong adsorbent like activated charcoal followed by concentration. Simultaneously, a simple and rapid large volume Direct Injection LC-MS method was optimized from the previous method to detectacrylamide without the resource and time-consuming SPE step. A comprehensive comparison between the efficiency and sensitivity of the two methods is made. Optimization of LC-MS parameters (column temperature, mobile phase composition and flow, collision energy, fragmentor voltage, capillary voltage or MRM transitions) allowed high detection sensitivity. Due to Acrylamide high polarity, a Synergi Fusion-RP column with amide polar embedded groups was chosen to achieve reasonable retention and peak shape for acrylamide with a short run-time of only 3 min. The two methods provided excellent sensitivity, with reasonably low LOQ values of $2 \mathrm{ng} / \mathrm{L}$ for the Offline-SPE-LC-MS method and $30 \mathrm{ng} / \mathrm{L}$ for the Direct Injection LC-MS method. Intra-day and inter-day precision (RSD\%) were 7.3 and 10.3\%, for the OfflineSPE-LC-MS method and 2.4\% and 6.2\%, respectively for the Direct Injection LC-MS method. The analysis of acrylamide was successfully performed in drinking water from different location consumers and water treatment plants in Romania. Acrylamide was found in drinking water samples with levels between 5.2 and $35.7 \mathrm{ng} / \mathrm{L}$ using the Offline-SPE-LC-MS method. The direct injection method can only be used for acrylamide levels higher than its $L O Q$ value (30 $\mathrm{ng} / \mathrm{L})$.
\end{abstract}

Keywords: acrylamide, offline-SPE-LC-MS, direct injection LC-MS, drinking water

Polyacrylamide is widely used in water treatment plants for the flocculation of suspended material and in many other products and activities: cosmetics [1], pesticides [2], grout, cement [3], explosives, food manufacturing [4], crude oil production [5], coatings for home appliances, building materials, adhesives [6], automotive parts and printing inks. The main source of acrylamide (AA) in the environment is the release of residual monomer from polyacrylamide used as flocculant in the treatment of raw water. Another significant source of acrylamide is the thermally processed food and itcan be formed in two ways: (i) by amino acids interaction (asparagine) with sugars in the presence of heat and (ii) food fats oxidation during frying process and their conversion to acrylic acid and acrolein. These molecules will interact with asparagine, in the presence of heat and form unusual amounts of acrylamide [7,8].

Acrylamide is considered as possible carcinogenic to humans and classified as a Group 2A carcinogen by the International Agency for Research on Cancer (IARC) [9] and the World Health Organization (WHO) guideline value associated with a lifetime cancer risk is $0.5 \mu \mathrm{g} / \mathrm{L}$ in drinking water [10]. Concerning its use in drinking water supplies, the USEPA set a maximum contaminant level goal (MCL) for acrylamide of zero and requires water suppliers to demonstrate that the AA monomer is present at concentrations lower than $0.5 \mu \mathrm{g} / \mathrm{L}$ [11]. In Europe, the REACH regulation limited the acrylamide content in commercialized products to $<0.1 \%$ for grouting applications after 2012 [12]. Acrylamide has also been regulated in European countries by the Drinking Water Directive which imposes a maximum admissible concentration of $0.1 \mu \mathrm{g} / \mathrm{L}$ for water intended for human consumption [13].

The very low concentration of different types of pollutants in environmental samples, usually at parts per trillion levels, requires the isolation of interest analytes by extraction procedures and extremely sensitive analytical methods [14-16]. Because of its physico-chemical properties, such as low molecular weight (M.W. $=71.1 \mathrm{~g} /$ mol) and significant polarity (table 1), this molecule is difficult to separate and to detect using either GC-MS or LC-MS methods.

Acrylamide has been determined in environmental water samples by gas chromatography using electron capture (GC-ECD) or mass spectrometric (GC-MS) detection [1720]. These methods require derivatization and liquid-liquid

Table 1

ACRYLAMIDE PHYSICO-CHEMICAL PROPERTIES AND STRUCTURE

\begin{tabular}{|l|c|}
\hline Property & Acrylamide \\
\hline Chemical Structure & \\
\hline Molecular Mass (g/mol) & \\
\hline log Kow & $71.08^{-1}$ \\
\hline Density (g/ $\left.\mathrm{cm}^{5}\right)$ & -0.67 \\
\hline Melting point $\left({ }^{\circ} \mathrm{C}\right)$ & 1.13 \\
\hline Water Solubility $(\%)$ & 84.5 \\
\hline
\end{tabular}


extraction before analysis. However, the efficiency of derivatization is often variable and the process is time consuming and requires usually additional LLE extraction before GC separation. To avoid the derivatization procedure, high-performance liquid chromatography (HPLC) is a suitable method for determination of acrylamide. While HPLC with UV detection suffers from poor detection limits $(3-10 \mu \mathrm{g} / \mathrm{L})[21,22]$ due to lack of chromophores, liquid chromatography tandem mass spectrometry (LC-MS/MS) was more recently employed due to its high selectivity and increased sensitivity. The trace amounts of acrylamide present in drinking water samples, involves the necessity to concentrate the samples before LC-MS analysis, which might also be problematic. Due to its high-water solubility (40\%), AA is poorly retained on most solid-phase extraction (SPE) adsorbents [23].

The objective of the present study was to develop and validate two methods - an Offline SPE-LC-MS and a Direct Injection LC-MS method, both able to detect low levels of acrylamide in drinking water, and to compare their efficiency and sensitivity (LOQ).

\section{Experimental part}

\section{Reagents and chemicals}

Standards of Acrylamide (AA) and isotopically labeled Acrylamide $\left({ }^{13} \mathrm{C}_{3}\right.$-Acrylamide, $\left.{ }^{13} \mathrm{C}_{3}-\mathrm{AA}\right)$ which was used as internal standard were purchased from Sigma-Aldrich. Methanol and acetonitrile of HPLC-grade purity were acquired from Merck and Formic Acid of $99 \%$ purity from Supelco. SPE activated charcoal cartridges (Supelclean Coconut Charcoal - $2 \mathrm{~g} / 6 \mathrm{~mL}$ ) were acquired also from Supelco (Bellefonte, PA, USA).

\section{LC-MS instrumentation and conditions}

Analyses were performed using an Agilent 1260 series LC system (Waldbronn, Germany) coupled with an Agilent 6410B triple-quadrupole mass spectrometer with electrospray ionization source (ESI). The chromatographic column was a Synergi Fusion RP $(150 \times 2.0 \mathrm{~mm}, 4.0 \mu \mathrm{m})$ from Phenomenex, the stationary phase being a $\mathrm{C} 18$ chain modified with polar embedded amide groups. All experiments were performed in isocratic elution conditions at a flow-rate of $0.2 \mathrm{~mL} / \mathrm{min}$. Mobile phase consisted of a binary mixture of $30 \% \mathrm{Aq}$. Formic acid $(0.1 \%)$ and $70 \%$ $\mathrm{MeOH}$. Optimized injection volumes of $10 \mu \mathrm{L}$ for the Offline SPE-LC-MS method and $50 \mu \mathrm{L}$ for the Direct injection LCMS method were used with water/MeOH (1:1) as sample diluent. MS detection was achieved using Multiple Reaction Monitoring (MRM) acquisition mode. Full-Scan MS spectra were acquired in the range 20 - $100 \mathrm{Da}$ to establish MRM transitions for AA and internal standard. Retention time, MRM transitions, fragmentor voltages, collision energies and other MS parameters are given in table 2. ESI ionization source was operated in positive mode with $300^{\circ} \mathrm{C}$ as the drying gas temperature, $6 \mathrm{~L} / \mathrm{min}$ drying gas flow, $40 \mathrm{psi}$ nebulizer pressure and $6000 \mathrm{~V}$ capillary voltage. SPE extraction of acrylamide and internal standard from drinking water was done using the semi-Automated extractor Dionex AutoTrace 280 from Thermo Scientific.

\section{Results and discussions}

\section{LC separation optimization}

Considering the significant polarity of the investigated analyte ( $\log$ Kow $=-0.67)$ and its low molecular weight, it was expected that this compound would not have significantretention on hydrophobic C18 columns and also might have problems of sensitivity for MS detection. For this reason, a C18 polar embedded column with amide polar groups was chosen to obtain a reasonable retention time and peak symmetry for the acrylamide and IS peaks. The C18 ligand gives normal retention for hydrophobic compounds while the polar embedded group provides enhanced retention for highly polar analytes like acrylamide (log Kow $=-0.67$ ). Various mobile phase compositions were tested for elution using differentorganic solvents $(\mathrm{ACN}, \mathrm{MeOH})$ and also different proportions between the aqueous and the organic solvent. The chosen mobile phase composition Aq. $0.1 \%$ formic acid $/ \mathrm{MeOH}=$ $30 / 70(\mathrm{v} / \mathrm{V})$ generated good peak shape and provided short retention time for AA peak ( $<3 \mathrm{~min})$. Other $L C$ instrumental parameters taken into account to increase $A A$ and ${ }^{13} C_{3}-A A$ peak area, peak efficiency and symmetry (peak shape) were the injection volume and column temperature. Injection volume range between 5 and $75 \mu \mathrm{L}$ and column temperature range from 15 to $45^{\circ} \mathrm{C}$ were tested. A reasonable peak shape for $A A$ and ${ }^{13} C_{3}-A A$ was achieved for injection volumes up to $50 \mu \mathrm{L}$. Above this value peak distortion appeared for both $A A$ and ${ }^{13} C_{3}-A A$. It is important to be mentioned that an injection volume of $50 \mu \mathrm{L}$ is very high for the used column ( $2.0 \mathrm{~mm}$ i.d.). Injection of large volumes in RP-LC can be employed if sample diluent is weaker than mobile phase [24]. Peak symmetry and peak efficiency of $A A$ and ${ }^{13} C_{3}-A A$ increased with temperature increase from 15 to $45^{\circ} \mathrm{C}$ and the latter value was thus chosen. Optimized conditions of the LC parameters allowed a short run-time of only 3 min. Figure 1 shows the MS/MS extracted chromatograms of Acrylamide and ${ }^{13} \mathrm{C}_{3}$ Acrylamide standard mixtures obtained using the two methods.

\section{MS detection optimization}

Method development for acrylamide detection implied optimization of all MS parameters to obtain lowest possible quantitation limit (LOQ) which is necessary to determine extremely low levels of acrylamide expected to occur in drinking water $(\mathrm{ng} / \mathrm{L})$. Thus, all detection parameters of the triple quadrupole MS detector (QQQ) were modified to obtain maximum sensitivity (fig. 2). All electrospray ionization source parameters were also modified in a wide range to obtain highestionization efficiency for the analytes in terms of peak area (detector response) butalso in terms of signal-to-noise ratio (S/N). Collision energy (CE) applied in the collision cell (Q2) to the precursor ion to generate the product ion of the MRM transition was varied in the range 5-15 V. The highest peak area value was obtained for a collision energy of 10V. Using the optimum collision energy values, the MS optimization was continued with fragmentor voltage (voltage used to accelerate, focus and transfer ions from the ionization source to the first

\begin{tabular}{|l|c|c|c|c|c|}
\hline \multicolumn{1}{|c|}{ Compound } & $\begin{array}{c}\text { MRM } \\
\text { transitions }\end{array}$ & $\begin{array}{c}\text { Fragmentor } \\
\text { voltage (V) }\end{array}$ & $\begin{array}{c}\text { Collision } \\
\text { energy (V) }\end{array}$ & $\begin{array}{c}\text { Cell Voltage } \\
\text { (V) }\end{array}$ & Polarity \\
\hline${ }^{13} C_{3}$-Acrylamide & $75 \rightarrow 58(\mathrm{Q})$ & 80 & 10 & 1 & + \\
\hline Acrylamide & $72 \rightarrow 55(\mathrm{Q})$ & 80 & 10 & 1 & + \\
\hline
\end{tabular}

Table 2

MS PARAMETERS FOR THE DETECTION OF ACRYLAMIDE AND LABELED INTERNAL STANDARD (MRM TRANSITIONS, FRAGMENTOR VOLTAGE, COLLISION ENERGY ANS OTHER MS PARAMETERS) 

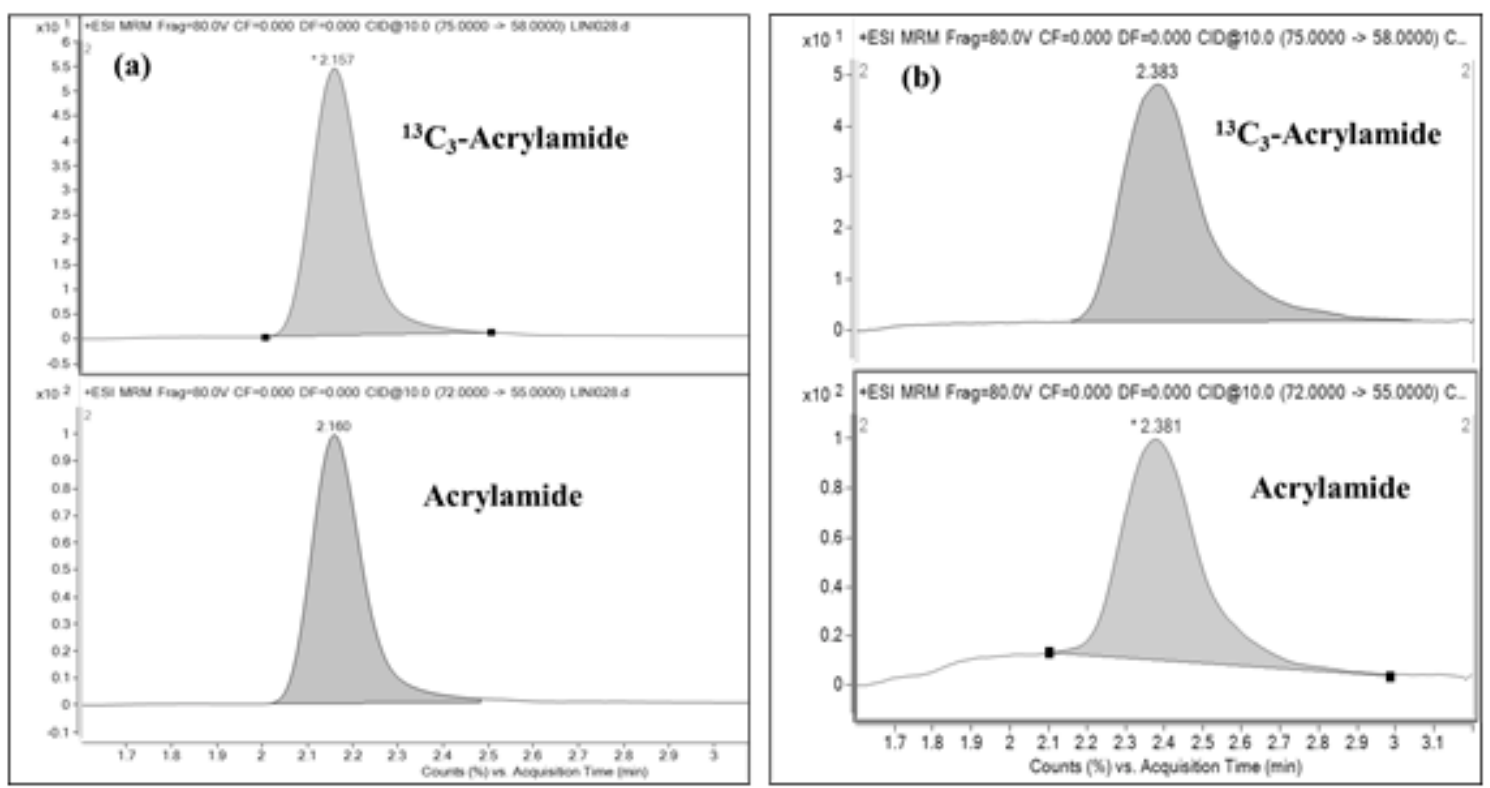

Fig. 1. MRM overlaid extracted ion chromatograms of (a) $50 \mu \mathrm{g} / \mathrm{L} \mathrm{AA}$ and $100 \mu \mathrm{g} / \mathrm{L}{ }^{13} \mathrm{C}_{3}$-Acrylamide (SI) using the Offline-SPE-LC-MS method and (b) $0.5 \mu \mathrm{g} / \mathrm{L} \mathrm{AA}$ and $1 \mu \mathrm{g} / \mathrm{L}{ }^{13} \mathrm{C}_{3}$-Acrylamide (SI) using the Direct injection LC-MS method
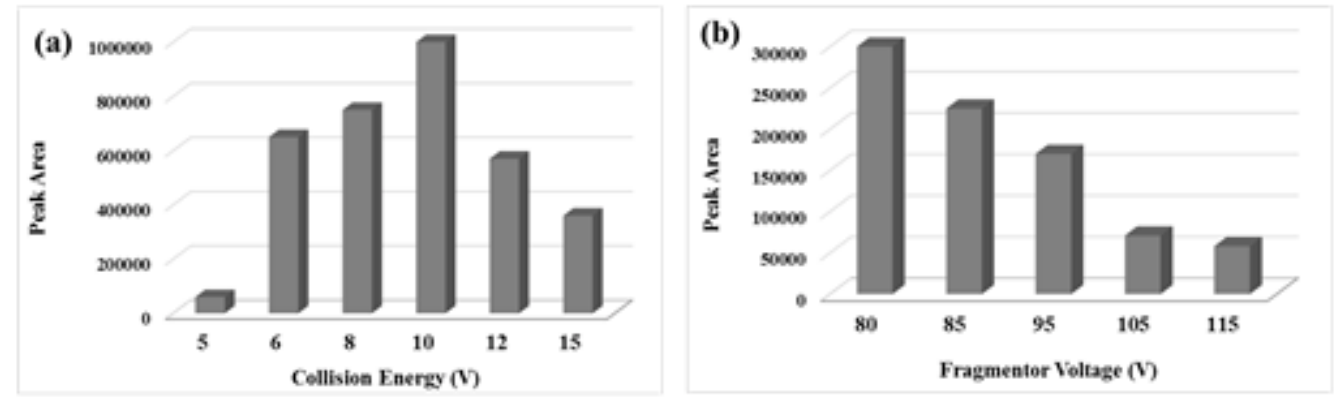

Fig. 2. Peak area variation of Acrylamide during MS optimization function of:

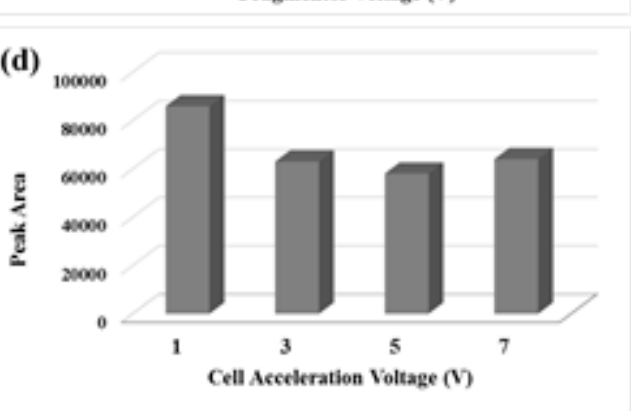

(a) Collision energy;

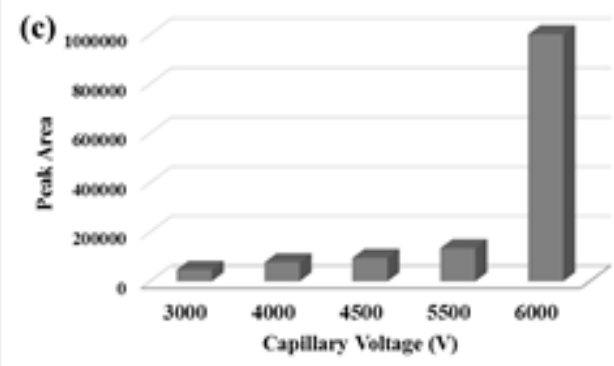

(d)

(b) Fragmentor voltage;

(c) Capillary Voltage and

(d) Cell accelerator voltage

quadrupole). The values selected tor testing were between 80 and $115 \mathrm{~V}$ ( $5 \mathrm{~V}$ steps). Fragmentor voltage of $80 \mathrm{~V}$ generates the highest transfer of acrylamide precursor ion to the first quadrupole. The same procedure was applied for the capillary voltage in the range $3000-6000 \mathrm{~V}$ and to the cell accelerator voltage in the range $1-7 \mathrm{~V}$. The final chosen values ( $6000 \mathrm{~V}$ capillary voltage and $1 \mathrm{~V}$ for cell accelerator voltage) generate maximum peak area as can be seen in figure 2 .

Following MS detection optimization procedure, the parameters which generated maximum sensitivity were selected and are given in table 3 .

\section{Offline-SPE extraction}

The optimization of the LC-MS analysis method was followed by optimization of the solid phase extraction parameters (using semi-automated SPE extractor) to allow concentration of acrylamide from drinking water samples at ppt level up to ppb level which represents the usual instrumental quantitation limit for MS/MS detection with Triple Quadrupole analyzers. Acrylamide was extracted from $250 \mathrm{~mL}$ water samples using activated charcoal SPE cartridges. This adsorbent is usually efficient for highly polar molecules like $A A$ and ${ }^{13} C_{3}-A A$. The cartridges were preconditioned with $5 \mathrm{~mL}^{3}$ of methanol and $5 \mathrm{~mL}$ of

\begin{tabular}{|l|l|}
\hline MS parameters & Optimized values \\
\hline Ionization source: & Electrospray (positive mode) - ESI(+) \\
Drying gas temperature: & $300^{\circ} \mathrm{C}$ \\
Drying gas flow: & $6 \mathrm{~L} / \mathrm{min}$ \\
Nebulizer pressure: & $40 \mathrm{psi}$ \\
Capillary Voltage: & $6000 \mathrm{~V}$ \\
Collision Energy: & $10 \mathrm{~V}$ \\
Fragmentor voltage: & $80 \mathrm{~V}$ \\
MS mode: & Multiple Reaction Monitoring (MRM) \\
Dwell time: & $160 \mathrm{msec}$ \\
Cell Accelerator Voltage: & $1 \mathrm{~V}$ \\
\hline
\end{tabular}

Table 3

OPTIMIZED MS PARAMETERS THAT GENERATE MAXIMUM SENSITIVITY FOR ACRYLAMIDE 
ultrapure water at $5 \mathrm{~mL} / \mathrm{min}$. Before extraction, $1 \mathrm{~mL}$ of ${ }^{13} \mathrm{C}_{3}-\mathrm{AA}(100 \mu \mathrm{g} / \mathrm{L})$ was added as surrogate IS to each water sample. The samples were passed through the SPE cartridges. Before elution, the cartridges were dried for 30 min. Elution was done with $10 \mathrm{~mL}$ of methanol at a flow rate of $1 \mathrm{~mL} / \mathrm{min}$. Under a gentle nitrogen stream, the extracts were evaporated to dryness and re-dissolved with $1.0 \mathrm{~mL}$ of water/MeOH (1:1) and transferred into injection vials prior to LC-MS analysis. Thus, a concentration factor of 250 was obtained using the SPE extraction.

\section{Method validation}

To accountfor their performance, the developed OfflineSPE-LC-MS and Direct injection LC-MS methods were validated with respect to specificity, linearity, precision, accuracy and limit of quantitation. MS detector response was tested and proved linear in the range $1-200 \mu \mathrm{g} / \mathrm{L}$ for Offline-SPE-LC-MS method and $0.05-2.0 \mu \mathrm{g} / \mathrm{L}$ for the direct injection LC-MS method. Both methods generated high correlation coefficients ( $\left.R^{2}>0.999\right)$ (fig. 3).

Instrumental LOQs for both methods were determined by injecting decreasing concentrations of acrylamide solutions until a $\mathrm{S} / \mathrm{N}$ of 10 was obtained (table 5 ). Intra-day and inter-day method precision was tested on 6 replicate samples by spiking $50 \mathrm{ng} / \mathrm{L}$ for Offline-SPE-LC-MS and 0.1 $\mu \mathrm{g} / \mathrm{L}$ acrylamide for the Direct injection method. Results obtained after validation procedure are given in Table 4. The methods proved to be precise with RSD\% values of $7.3 \%$ (intra-day) and $10.3 \%$ (inter-day) for Offline-SPE-LCMS method and $2.4 \%$ (intra-day) and 6.2\% (inter-day) for Direct injection LC-MS method.

Analyte recovery was calculated with internal standard correction as can be observed in table 5. Overall method LOQs were determined as $2 \mathrm{ng} / \mathrm{L}$ for Offline-SPE-LC-MS and $30 \mathrm{ng} / \mathrm{L}$ for Direct injection LC-MS method.
Table 4

RESULTS OBTAINED FOR INTRA-DAY AND INTER-DAY PRECISION BY SPIKING $50 \mathrm{ng} / \mathrm{L}$ ACRYLAMIDE FOR OFFLINE-SPE-LC-MS AND $0.1 \mu \mathrm{g} / \mathrm{L}$ FOR THE DIRECT INJECTION LC-MS METHOD

\begin{tabular}{|c|c|c|c|}
\hline \multicolumn{2}{|c|}{$\begin{array}{c}\text { Offline-SPE-LC-MS } \\
\text { RSD } \%\end{array}$} & \multicolumn{2}{|c|}{$\begin{array}{c}\text { Direct injection LC-MS } \\
\text { RSD } \%\end{array}$} \\
\hline Intra-day & Inter-day & Intra-day & Inter-day \\
\hline 7.3 & 10.3 & 2.4 & 6.2 \\
\hline
\end{tabular}

Comparing the performance of the two methods it can be observed that although the Offline-SPE-LC-MS one allows the detection of ultra-trace levels of acrylamide (LOQ $2 \mathrm{ng} / \mathrm{L}$ ), it requires a time-consuming SPE extraction procedure which takes about 3 hours being overall more expensive. The Direct injection LC-MS method on the other hand is more rapid (no sample preparation step), costefficient but allows quantitation of AA only for concentration levels higher than its LOQ value of $30 \mathrm{ng} / \mathrm{L}$. Nonetheless this value is more than 3 times lower than the European maximum admissible concentration $(0.1 \mu \mathrm{g} / \mathrm{L})$. The Direct injection method is more precise than the Offline-SPE method due to lack of additional preparation steps and does not suffer from analyte loss during extraction as opposed to the latter ( $40.2 \%$ absolute recovery). Acrylamide loss during SPE is compensated by the labeled internal standard addition, but the loss affects method LOQ.

\section{Acrylamide occurrence in drinking water}

The developed Offline-SPE-LC-MS method was used for detection of acrylamide ultra-trace levels in drinking water samples collected from ten different private consumers (S1-S10) and five water treatment plants (S11-S15) all located in NeamtCounty, Romania. The values determined for acrylamide by both Offline-SPE-LC-MS and Direct injection LC-MS methods are shown in table 6.

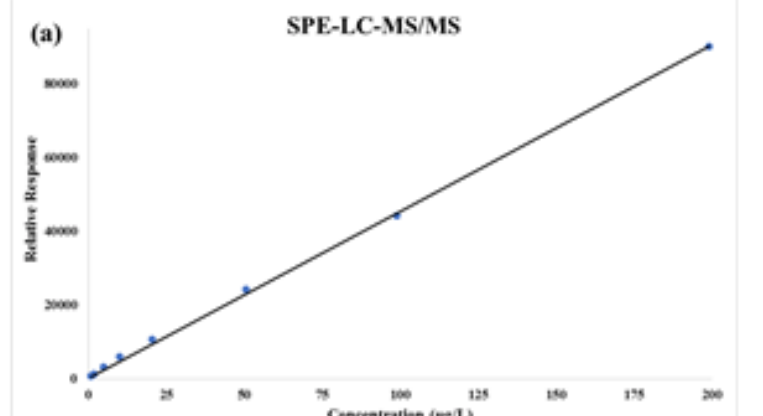

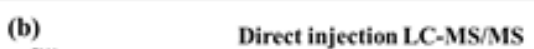

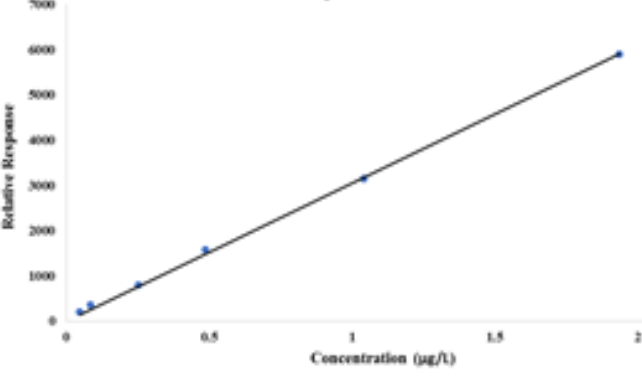

Fig. 3. Linear MS detector response in the range

(a) 1 - $200 \mu \mathrm{g} / \mathrm{L}$ for Offline-SPE-LC-MS method and

(b) $0.05-2.0 \mu \mathrm{g} / \mathrm{L}$ for Direct injection LC-MS method

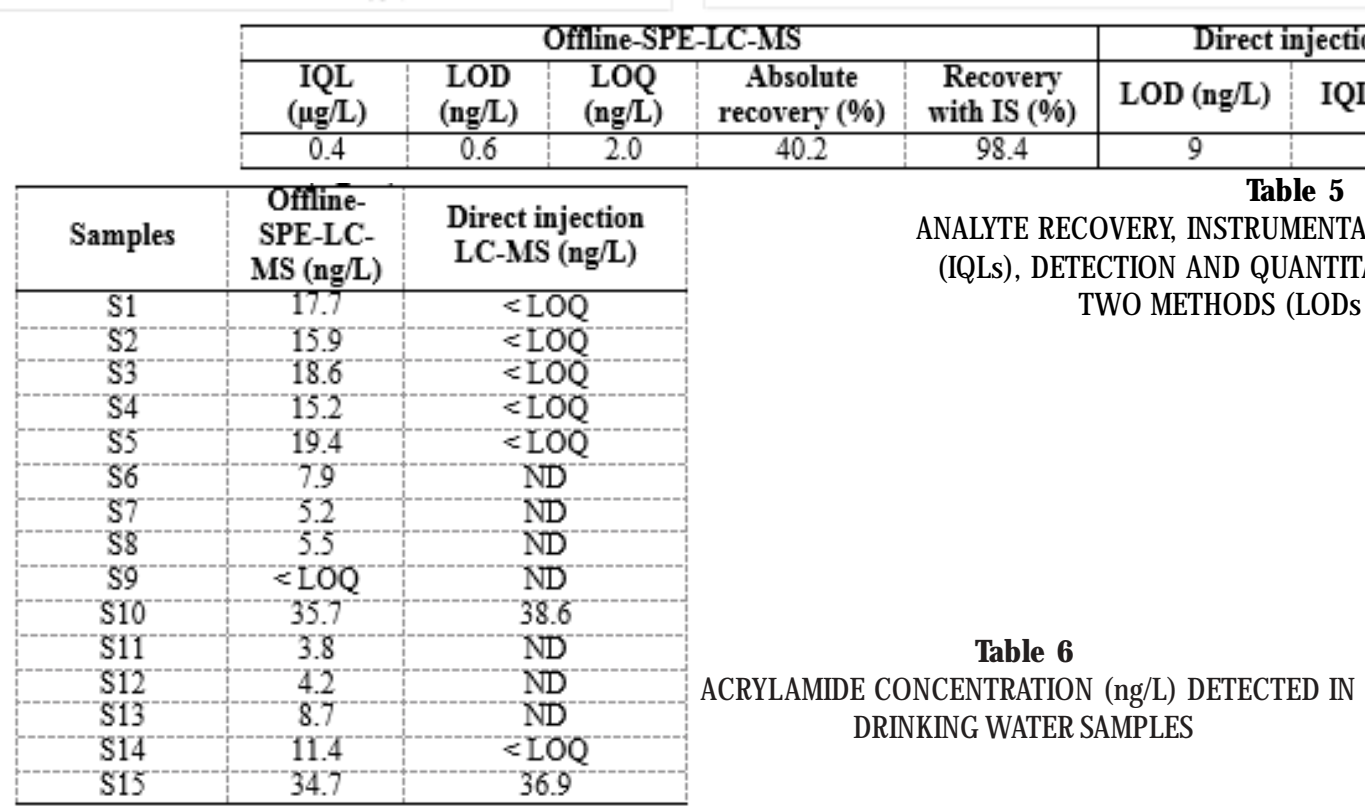


Using the Offline-SPE-LC-MS method, Acrylamide was determined to be present in almost all analyzed samples (except for S9) with concentration values between 5.2 and $35.7 \mathrm{ng} / \mathrm{L}$. Due to low levels of acrylamide in tested drinking water samples, the Direct injection LC-MS method was able to quantitate acrylamide only in S10 and S15 samples because of the higher LOQ value ( $30 \mathrm{ng} / \mathrm{L})$. All analyzed samples (private consumers and water treatment plants) generated AA levels below the maximum admissible concentration of $0.1 \mu \mathrm{g} / \mathrm{L}$. Obtained values from Romania drinking water samples, are of the same order of magnitude with those obtained in other studies from Europe $[25,26]$

\section{Conclusions}

In this study two LC-MS methods were developed and validated for detection of acrylamide in drinking water samples. The first method was an Offline-SPE-LC-MS method (LOQ $2 \mathrm{ng} / \mathrm{L}$ ) and the second was a Direct Injection LC-MS method (LOQ $30 \mathrm{ng} / \mathrm{L}$ ) derived from the former but without the SPE extraction and with an enlarged injection volume $(50 \mu \mathrm{L})$. The Offline-SPE-LC-MS method is more sensitive than the Direct injection LC-MS method but requires SPE extraction and concentration which means additional costs and time per analysis. LC-MS analysis was done in less than 3 min for both methods. Chromatographic conditions and MS parameters were optimized in order to obtain highest method sensitivity. In drinking water samples, the recovery of the Offline-SPELC-MS method was $98 \%$ due to surrogate internal standard correction. For the solid phase extraction method, the values obtained for intra-day precision was $7.3 \%$ and $10.3 \%$ for intra-day precision respectively. Regarding the direct injection method precision, RSD values were $2.4 \%$ for interday and $6.2 \%$ for intra-day precision. Analysis of drinking water samples was done using both methods. Acrylamide was found in drinking water samples with levels betw een 5.2 and $35.7 \mathrm{ng} / \mathrm{L}$ using the more sensitive Offline-SPE-LCMS method. Direct injection method can be used for Acrylamide levels higher than its LOQ $(0.03 \mu \mathrm{g} / \mathrm{L})$ which is 3 times lower than the maximum admissible concentration stated in Europe $(0.1 \mu \mathrm{g} / \mathrm{L})$.

Acknowledgements. The authors acknowledge the financial support offered by The National Research Program Nucleu through Agreement no. 38N/2018, Project code PN 18050101.

\section{References}

1. CALO, E., KHUTORYANSKIY, V. V., Eur. Polym. J., 65, 2015, p. 252. 2. SOJKA, R. E., BJ ORNEBERG, D. L., ENTRY, J. A., LENTZ, R. D., ORTS, W. J., Adv. Agron, 92, 2007, p. 75.
3. RAI, U. S., SINGH, R. K., Mat. Sci. Eng. A., 392, 2005, p. 42. 4. NEGOITA, M., ADASCALULUI, A., IORGA, E., CATANA, L., CATANA, M., BELC, N., Rev. Chim. (Bucharest), 66, no. 4, 2015, p. 464.

5. BAI, B., ZHOU, J., YIN, M., Petrol. Explor. Develop., 42, no. 4, 2015, p. 525.

6. BAIT, N., GRASSL, B., BENABOURA, A., DERAIL, C., J. Adhes. Sci. Technol., 27, no. 9, 2013, p. 1032.

7. ROMMENS, C. M., YAN, H., SWORDS, K., RICHAEL, C., YE, J., Plant. Biotechnol. J., 6, no. 8, 2008, p. 843.

8. S. E. K. TEKKELI, C. ONAL, A. ONAL, Food Anal. Methods, 5, 2012, p. 29.

9.*** International Agency for Research on Cancer. Some industrial chemicals. Lyon: IARC, 60, 1994, p. 389.

10.*** Guidelines for Drinking Water Quality, Recommendations, WHO, Geneva, 1, 1993, p. 72.

11.*** US Environmental Protection Agency, National primary drinking water regulation. Washington DC, 2002.

12.*** European Parliament, European Council Registration, Evaluation, Authorisation and Restriction of Chemicals (REACH), establishing a European Chemicals Agency. no 1907, 2006.

13.*** European Council, Directive 98/83/EC of 3 November 1998 on the quality of water intended for human consumption. Off. J. Eur. Commun. L330. European Union Brussels, 1998.

14. PAUN, I., IANCU V. I., CRUCERU, L., NICULESCU, M., CHIRIAC, F. L., Rev. Chim.(Bucharest), 69, no. 1, 2018, p. 27.

15. CHIRIAC, F. L., CRUCERU, L., NICULESCU M., PASCU, L. F., LEHR, C. B., GALAON, T., REV.CHIM. (Bucharest), 68, no. 8, 2017, p. 1685. 16.MEDVEDOVICI, A., ALBU, F., SORA, I.D., UDRESCU, S., GALAON, T., DAVID, V., Biomed. Chromatogr., 23, 2009, p. 1092.

17. ZHANG, Y., ZHANG, G. Y., ZHANG, Y. J. Chromatogr. A, 1075, 2005, p. 1.

18.***Method 8032A: Acrylamide by gas chromatography, U.S. EPA: Washington, DC, 1996.

19. YAMINI, Y., GHAMBARIAN, M., ESRAFILI, A., YAZDANFAR, N., MORADI, M., Int. J. Environ. Anal. Chem., 92, 2012, p. 1493.

20. *** Method 603: Acrolein and acrylonitrile, U.S. EPA, 1984.

21. WEIDEBORG, M., KALLQVIST, T., ODEGARD, K. E., SVERDRUP, L. E., VIK, E. A., Water Res., 35, 2001, p. 2645.

22. SORA, I., GALAON, T., UDRESCU, S., NEGRU, J., DAVID, V., MEDVEDOVICI, A., J. Pharm. Biomed. Anal., 43, 2007, p. 1437 23. ROSEN, J., NYMAN, A., HELLENAS, K. E., J. Chromatogr. A, 1172, 2007, p. 19

24. DAVID, V., GALAON, T., ABOUL-ENEIN, H.Y., J. Chromatogr. A, 1323, 2014, p. 115.

25. DEARMOND, P., D., DIGOREgORIO, A., L., Anal. Bioanal. Chem., 405, 2013, p. 4159.

26. W. J. BACKE, V. YINGLING, T. JOHNSON, J. Chromatogr. A, 1334, 2014, p.72.

Manuscript received: 17.08 .2018 